\title{
Sustainability principles put into practice: case studies of network analysis in Swiss climate change adaptation
}

\author{
Karin Ingold · Jörg Balsiger
}

Received: 20 May 2013/Accepted: 14 December 2013/Published online: 30 December 2013

(C) Springer-Verlag Berlin Heidelberg 2013

\begin{abstract}
Climate adaptation policies increasingly incorporate sustainability principles into their design and implementation. Since successful adaptation by means of adaptive capacity is recognized as being dependent upon progress toward sustainable development, policy design is increasingly characterized by the inclusion of state and non-state actors (horizontal actor integration), cross-sectoral collaboration, and inter-generational planning perspectives. Comparing four case studies in Swiss mountain regions, three located in the Upper Rhone region and one case from western Switzerland, we investigate how sustainability is put into practice. We argue that collaboration networks and sustainability perceptions matter when assessing the implementation of sustainability in local climate change adaptation. In other words, we suggest that adaptation is successful where sustainability perceptions translate into cross-sectoral integration and collaboration on the ground. Data about perceptions and network relations are assessed through surveys and treated via cluster and social network analysis.
\end{abstract}

Electronic supplementary material The online version of this article (doi:10.1007/s10113-013-0575-7) contains supplementary material, which is available to authorized users.

K. Ingold $(\bowtie)$

Institute of Political Science and Oeschger Center for Climate

Change Research, University of Berne, Fabrikstrasse 8,

3012 Bern, Switzerland

e-mail: karin.ingold@ipw.unibe.ch

K. Ingold

EAWAG, Dübendorf, Switzerland

J. Balsiger

Department of Geography and Environment, University

of Geneva, Av. Pont-d'Arve 40, 1211 Genève, Switzerland

e-mail: joerg.balsiger@unige.ch
Keywords Climate change adaptation - Sustainability · Local communities $\cdot$ Social network analysis

\section{Introduction}

Mountain regions are very sensitive to the impacts of climate change. Extreme topographic and ecological conditions magnify the effects of temperature increases on the frequency of extreme events such as floods and droughts (IPCC 2007). The Upper Rhone region in the Alpine area of southern Switzerland is a typical case: This region has, in the past, been heavily hit by severe flood events, to which it responded using infrastructure and land management projects. As shown elsewhere, the design of such adaptation policies is primarily located at a lower institutional level affecting local systems and regional communities (Wilson 2006). Since successful adaptation by means of adaptive capacity is recognized as being dependent upon progress toward sustainable development (Smit and Pilifosova 2001), policy design is increasingly characterized by sustainability characteristics, such as the inclusion of state and non-state actors (horizontal actor integration), cross-sectoral collaboration, and inter-generational planning perspectives (Jänicke and Jörgens 2006; Bolleyer and Börzel 2010).

Comparing four case studies in Swiss mountain regions, three located in the Upper Rhone region and one case from western Switzerland, we investigate how sustainability is put into practice. We argue that collaboration networks and sustainability perceptions matter when assessing the implementation of sustainability in local climate change adaptation. In other words, we suggest that adaptation is successful where sustainability perceptions translate into cross-sectoral integration and collaboration on the ground. 
Data about perceptions and network relations are assessed through surveys and treated via cluster and social network analysis. The absence of divergent sustainability perceptions, weak conflict lines, and strong inter-group collaboration would then all be indicators that cross-sectoral policy coordination does occur. Through this horizontal and vertical actors' collaboration, sustainable resource management and long-term adaptive capacity could be more easily achieved.

\section{Climate change adaptation and sustainability}

The adaptation of human societies to international changes such as global warming is shaped, among other factors, by adaptive capacity and vulnerability (Smit and Wandel 2006). To date, most studies on vulnerability and adaptive capacity have focused on developing countries (e.g., Adger 2003; Eakin and Lemos 2010), where access to financial and technical resources has a decisive role. More recently, a growing number of scholars have begun to examine these issues in the context of industrialized countries, where resource availability is often less important than institutional and organizational aspects (Davies 2005; Pelling et al. 2008; Wall and Marzall 2006).

The principle of sustainability has long been linked to climate change and natural resource management. In its Third Assessment Report of 2001, the IPCC suggested that "enhancement of adaptive capacity reduces the vulnerability of sectors and regions to climate change, including variability and extremes, and thereby promotes sustainable development and equity." The integration of environmental, economic, and social dimensions of well-being-which amounts to the most general definition of sustainabilityalso implies more concerted relations between actors representing these interests. This is reinforced by the tendency of climate change to mostly affect local communities, where attention shifts from the vertical (levels of decision) to the horizontal axis and where state and non-state actors representing different economic sectors jointly engage in policy making (Bolleyer and Börzel 2010).

The temporal variability of climate change impacts, which includes slowly evolving long-term dynamics, points to another link between adaptation and sustainability, namely inter-generational perspectives. Climate change impacts on natural resources are of incremental nature, causing fundamental long-lasting changes requiring action ranging from short and medium term to inter-generational. But although often needed, short-term action may be in contradiction with the core concepts of sustainability. First, participatory planning that integrates a multitude of actors representing different sectors makes heavy demands on time and financial resources. Second, the adoption of a long-term perspective has to be coordinated with shortterm or ad hoc interventions.

Despite these challenges, most current climate adaptation strategies seek to follow the principle of sustainable development, which is typically invoked in abstract terms with reference to general definitions emanating from global agendas and discourses. Variations in the means by which the principle is understood and applied in practice remain an issue that has, thus far, received little scholarly attention. The aim of this paper was to address this lacuna. In order to do this, we examine how cross-sectoral collaboration and long-term actors' collaboration (the two core characteristics of sustainability in relation to climate adaptation, as outlined above) are put into practice. We do so by investigating how actors perceive sustainability and whether actors with different sustainability priorities and representing different interests still manage to collaborate in the design of local climate adaptation policies.

\section{Sustainability perceptions by involved stakeholders}

Sustainable development has become a persuasive global norm, referenced in preambles to international treaties, anchored in national constitutions and strategies, and applied in myriad of ways at local levels (Parris and Kates 2003; Hamdouch and Zuindeau 2010). While the bulk of scholarly and practitioner literature has focused on developing harmonized criteria and indicators for sustainable development, little work has systematically examined the variation in, and comparison of, localized understandings of sustainability (Hartmuth et al. 2008).

Some scholars have suggested that there is no single way to pursue sustainability, but rather a coexistence of complementary institutional arrangements which society as a whole might take advantage of (Layard 2001). They have emphasized, for example, that sustainability indicator systems ought to enable the sustainability-based management of local affairs and thus need to take local circumstances into account (Gehrlein 2004). If the concept of sustainability is to serve as a benchmark for action, the actors involved are compelled to particularize the concept and situate it in their national or local context. Hence, any analysis of local actions that promotes sustainable development has to address how actors understand the concept and how such understandings translate into institutional arrangements and collective engagement. Knowledge of these understandings and how they vary allows observers to identify "communities of practice" (Wenger 2000) and generate insights into the potential for progress toward sustainable development. In turn, the degree to which sustainability perceptions manifest in cross-sectoral integration and long-term actor collaboration can provide 
insights into prevailing adaptive capacities and thus the prospects of adaptation to climate change.

Analyzing actors' collaboration through a network approach

One promising approach used to investigate whether actors (representing similar or different sustainability perceptions and interests) collaborate and are integrated in local or multi-level climate adaptation policies is social network analysis (SNA; Kenis and Schneider 1991). Contrary to other analytical tools that mainly concentrate on attributes of cases for explaining given phenomena, SNA focuses on network relations between cases and is based on the assumption that relationships between interacting units are important (Wasserman and Faust 1994). Traditionally, network boundaries were set and actors identified following the hierarchical organization of public policies (Laumann and Knoke 1987). To account for the complexity of environmental problems, current natural resource policy studies (Crona and Bodin 2006; Prell et al. 2009) and climate adaptation policies in particular (Ingold et al. 2010; Lubell and Fulton 2007) have redefined the network boundaries to account for the multi-level, cross-sectoral and transboundary characteristics of actor identification.

Network analysis in sustainability research (see Newman and Dale 2007) points out (1) the relevance of the quality of ties (strong vs. weak; frequent vs. sporadic; unilateral vs. reciprocal interaction; see also Ingold et al. 2010) and (2) the relationship between similar or different actor types (homophily vs. heterophily). Such an analysis enables us to account for the first sustainability dimension introduced above, namely the degree of integration of diverse actor types representing different sectors, decisional levels, sustainability priorities, and interests.

Research on sustainability and social capital additionally emphasizes the important role of bonding ties, enhancing trust and cohesion (Coleman 1990), and bridging ties, supporting innovation and flexible development of structures and processes (Newman and Dale 2007). This relational perspective on social capital and innovation then also provides insights into how coordination and network relations may foster the adaptive capacity on community levels (Pelling and High 2005). The analysis of cross-sectoral and multi-level collaboration within climate adaptation projects investigated here will not only answer the question of whether actors involved are representing ecological, social, and economic priorities. It also gives us a first insight into how collaboration across groups of actors is shaped: The study of interaction patterns at a given point in time allows, at the very least, for a discussion of the potential for long-term interaction and collaboration in climate adaptation.

\section{Materials and methods}

Case studies

Four climate adaptation projects are compared here; three of them are situated along the river Rhone in the southern Swiss canton of Valais, and one in western Switzerland. We added the fourth project to add diversity in context, natural conditions and region-specific institutional settings.

In 1987, 1993, and 2000, the Upper Rhone Valley experienced severe floods that caused costly damage to infrastructure and agricultural land. As a reaction to that, the canton set up three types of climate adaptation projects.

The first case consists of the Priority Measures Visp (PM Visp). It is mainly an infrastructural project concerning the small industrial town of Visp and should protect it from major flood events. Visp is traversed by the Rhone and acts as an important traffic corridor linking the country's north and south. The aim of the PM Visp is to protect the region's local communities from a 100-year flood event with an estimated spatial impact of more than 1,000 ha and damage of more than 2 billion euros. PM measures started in 2002 and are expected to be completed in 2013.

The second case of interest is a project for the elaboration of a Regional Development Concept (RDC). The RDC concerns a much larger area than PM Visp, ranging from the historical town Brig in the north to Salgesch in the south of the upper Valais. RDC aimed at defining longterm regional development objectives to take anticipatory climate adaptation measures.

The third case under investigation, also located in the Upper Rhone Valley, is the land reallocation project Brigerbad-Lalden-Visp (LR BLV). It is a complementary project to the PM Visp and is designed to compensate land owners for the loss of agricultural surface required for widening the riverbed. The reform beneficiaries are required to form a land management cooperative. IM negotiations began in 2008 .

The fourth case is a natural park project and is located in the western part of Switzerland. The Parc Jura Vaudois (PJV) is situated on the high plateau of the Valley de Joux that lies just at the border with France at about $1000 \mathrm{~m}$. It stretches over around $35 \mathrm{~km}$ (20 km in Switzerland) from southwest to northeast. The PJV was founded in 1971, and its first aim was to protect the typical scenic beauty of the region. In 2013, the PJV obtained the designation "regional nature park," a nationwide label for special areas where regional development integrates socioeconomic and nature protection goals (FOEN 2009). Besides land-use changes, wooded pastures are also highly sensitive to temperature rises and changes in precipitation patterns (Gavazov et al. 2013). The integrated management of the PJV should thus 
conciliate conflicts between resource use and nature protection, which may arise through climate change impacts.

In all four projects, the introduction of the principles of sustainability was formally defined by authorities. In the cases of the PM Visp and LR BLV, the Federal Office for the Environment (FOEN) attached its financial support to the condition of implementing a participatory process integrating different state and non-state actors for the design of measures and procedures. The same is true for the attribution of park labels-here in the case of PJV, where again, the FOEN asks for coordination among actors representing different decisional levels and sectors. Finally, for the RDC, the canton asked for the creation of different working groups representing economic, political, social, and environmental concerns.

\section{Data and material}

For the definition of the key actors in the four case studies, we rely on the classical combination of decisional and reputational approaches. In line with Knoke et al. (1996, 7), formal organizations, rather than individuals, stand in the foreground of today's politics. Actors in this research are therefore defined as organizations integrated into the policy design and implementation of the three resource projects. Following the decisional approach, actors formally implicated in the decision-making of regional resource management policies are identified. This first list was completed by actors who were mentioned as very powerful by two to five interviewed experts in each region. In the end, we had a set of 39 actors for the PJV; 38 and 35, respectively, for the PM Visp and the RDC; and 27 actors for BLV. Each actor received a standardized questionnaire via regular mail. The response rate ranged between 44 and $58 \%$ for the four cases. In Table 1, the response rates are displayed: As our aim was to investigate local governance settings, we also outlined the involvement and the respective response rate for local actors.

The questionnaire was split into three parts: One part consisted of a set of questions related to the priorities each organization gives to the following three dimensions of sustainability: natural resource protection (ecological dimension); civil society concerns (mainly related to the protection of the communities from climatic change impacts; social dimension); and the economic performance of the region (economic dimension). Asking stakeholders to indicate their priorities and preferences regarding these three sustainability dimensions allows for a diverse, individual definition and interpretation of sustainability. Given the complexity and multi-dimensionality of sustainability, as outlined above, it seems to make sense to allow for this diversity among actors' priorities and perceptions. This multi-dimensionality is thus also an important precondition for the cluster analysis, as introduced below.

The second part of the questionnaire was related to the content of the respective project. More concretely, the different objectives and goals were identified for every project: Such goals and objectives are very project related, and through a within-case comparison, we try to account for the potential divergence of interests among involved organizations. Actors could express their position toward the respective issue. More details about those sets of questions are outlined in the analysis and in Appendix 1 in Electronic Supplementary Material (ESM). Actors could evaluate the respective statements as follows: (1) completely agree; (2) partially agree; (3) partially disagree; and (4) completely disagree.

The final part of the questionnaire included questions about the actors' relational profiles toward all other organizations integrated in the respective project. More concretely, and to conduct a formal social network analysis (SNA; Scott 2000; Wasserman and Faust 1994), survey participants were asked to indicate collaboration relations they shared with all identified actors in the studied project.

Research design and methods

The research design focusing on sustainability perceptions and network relations to investigate how sustainability principles are put into practice is outlined hereafter. As
Table 1 Data and descriptive network statistics

Density indicates the number of observed relations in proportion to the maximal number of relations possible in a network; number of ties is the frequency of relations observed in the respective network

\begin{tabular}{|c|c|c|c|c|}
\hline & \multirow[t]{2}{*}{ PM Visp } & \multicolumn{2}{|c|}{ Upper Rhone Valley } & \multirow{2}{*}{$\begin{array}{l}\text { Western Switzerland } \\
\text { PJV }\end{array}$} \\
\hline & & $\mathrm{RDC}$ & LR BLV & \\
\hline Overall number of actors identified & 38 & 35 & 27 & 39 \\
\hline Number of local actors identified & $23(60 \%)$ & $28(80 \%)$ & $16(59 \%)$ & $13(33 \%)$ \\
\hline Response rate overall & $22 / 38(58 \%)$ & $20 / 35(57 \%)$ & $12 / 27(44 \%)$ & $18 / 39(46 \%)$ \\
\hline Response rate local actors & $12 / 23(52 \%)$ & $15 / 28(54 \%)$ & $5 / 16(31 \%)$ & $4 / 13(31 \%)$ \\
\hline \multicolumn{5}{|l|}{ Collaboration network } \\
\hline Density & $12 \%$ & $19 \%$ & $8 \%$ & $11 \%$ \\
\hline Number of ties & 172 & 229 & 54 & 168 \\
\hline
\end{tabular}


outlined above, two crucial characteristics of sustainability in relation to climate adaptation are of interest here: The cross-sectoral and long-term collaboration among actors involved in climate adaptation. Indicators for such collaboration patterns would be the absence of divergent perceptions, weak conflict lines, and strong inter-group collaboration, which is why the analysis is split into three subsequent steps.

First, and based on sustainability perceptions, a cluster analysis helps us to identify potential groups of actors displaying similar priorities in relation to the three sustainability dimensions. Therefore, survey participants mentioned what priority ( 3 high, 2 medium, and 1 low) the organization they represented attributed to the three sustainability dimensions: ecological, social, and economic. To detect potential groups of actors sharing similar sustainability definitions and displaying similar priorities, we engaged in three empirical steps (Nohrstedt and Ingold 2011; Weible and Sabatier 2005): First, those results were entered in a so-called actor $\times$ priority matrix with all actors of each project in the first row and the three priorities in the first line. Second, a Manhattan distance analysis was conducted to assess how similar or diverse the priorities actors attribute to the three dimensions were. The "actor $\times$ priority" matrix was therefore transformed into an "actor $x$ actor" matrix where every cell indicates the distance in priority attribution between two actors. Third, a potential group structure based on the Manhattan distance matrix was dispatched through a Tabu search clustering. Tabu search uses an algorithm of grouping together actors who are most similar into a cluster. Tabu search does this by searching for sets of actors who, if placed into a cluster, produce the smallest sum of within-cluster variances in the tie profiles. Thus, in our case, if actors in a cluster have similar sustainability priorities and therefore the smallest distances among each other, their variance around the cluster mean profile will be small. So, the partitioning that minimizes the sum of within-cluster variances minimizes the overall variance in tie profiles (Hanneman and Riddle 2005). Again, actors belonging to the same group or cluster therefore display similar sustainability priorities. Furthermore, we attributed a decisional or operational level (1 local, 2 cantonal, and 3 national) and a sector (1 private sector and economy; 2 political and administrative; and 3 civil society and environmental protection) to each actor. This allows us to see whether clusters of actors sharing similar sustainability priorities follow a multi-sector and multi-level structure or not. This is then a first indicator for the crosssectoral collaboration among actors and thus indicates a trend toward the implementation of sustainability principles.

In the second step, we try to further highlight potential reasons and conflict lines that may explain the clustering into actors' groups in the four cases. This analysis triangulates cluster results with the analysis of actors' interests they represent in the respective project. Appendix 1 (see ESM) displays the set of questions that were asked to each actor about the project he or she was involved in. We calculate the mean of the values that members of each cluster attribute to the respective statement (Appendix 3 in ESM, including significance tests to compare mean values among the clusters computed with ANOVA on STATA MP 11). Numbers closer to 1 indicate that the actors from the respective cluster agreed with the statements outlined in the questionnaire (see again Appendix 1, ESM), whereas numbers closer to 4 suggest that they strongly disagreed.

Finally, in the last part of the analysis, we will go one step further, as we wish to investigate whether actors belonging to different clusters (see steps 1 and 2) collaborate with each other. More concretely, we ask, "Do cluster members collaborate across group borders and conflict lines?" The answer to this question will then allow us to draw further conclusions about how effective cross-cluster collaboration may induce joint-learning processes and cross-sectoral and multi-level project coordination and, finally, allow for an effective and long-term implementation of sustainability principles.

To assess intra- and inter-cluster collaboration, we rely on density measures. Densities indicate the degree of connection within a network or within and across groups of actors. Density is calculated by dividing the observed number of relations between a certain set of actors by the total number of possible connections of this same set of actors (Hanneman and Riddle 2005; Scott 2000). Maximal density reaches 1 .

\section{Results}

The cluster analysis based on sustainability priorities clearly shows that in each of the four projects at least two clusters or groups of actors could be identified (Table 2). More concretely, one can see that actors within the same "sustainability" cluster tend to be closer to each other and more distant from the actors from other clusters (last column: "sustainability distance"; see Appendix 2 ESM). This is a first indicator that actors do not prioritize all sustainability dimensions in the same way and that some actors tend to have similar sustainability priorities to each other, but different priorities from other groups of actors.

The PM Visp project (Table 2) is a project largely designed by local and regional organizations that mainly includes private sector and civil societal/political interests. There exists one majority cluster including 19 actors and a minority cluster including three actors. Those three actors belong to both the cantonal and the local level and represent all three interests at stake. 
Table 2 Clusters following sustainability priorities

\begin{tabular}{|c|c|c|c|}
\hline & Actors & Level & Sector \\
\hline \multicolumn{4}{|l|}{ PM Visp } \\
\hline Cluster $1(n=19)$ & $\begin{array}{l}\text { EG-Visp, DIR-Visp, EG-BGL, EG-LAL, DDRK, VS-SNG, } \\
\text { VS-DLR, WSV, VS-DLJFW, FMV, SGAS, LON, DSM, } \\
\text { ITC, NPA, JFF, HZP, OLK, VS-SKFOW }\end{array}$ & $\begin{array}{l}\text { Local: } 10 \text { actors } \\
\text { Regional: } 9 \text { actors }\end{array}$ & $\begin{array}{l}\text { Private sector: } 10 \text { actors } \\
\text { Agencies: } 8 \text { actors } \\
\text { Civil soc/env: } 1 \text { actor }\end{array}$ \\
\hline Cluster $2(n=3)$ & EG-Bal, WWF, WLL & $\begin{array}{l}\text { Local: } 2 \text { actors } \\
\text { Regional: } 1 \text { actor }\end{array}$ & $\begin{array}{l}\text { Private sector: } 1 \text { actor } \\
\text { Agencies: } 1 \text { actor } \\
\text { Civil soc/env: } 1 \text { actor }\end{array}$ \\
\hline \multicolumn{4}{|l|}{$\mathrm{RDC}$} \\
\hline Cluster $1(n=15)$ & $\begin{array}{l}\text { EG-Varen, EG-Steg, DDRK, EG-Salgesch, EG-Raron, EG- } \\
\text { Gampel, EG-Bratsch, EMAC, EG-Visp, Leuk T, DL LW, } \\
\text { RW OW, DL Strassen, Areaplan, Wander }\end{array}$ & $\begin{array}{l}\text { Local: } 10 \text { actors } \\
\text { Regional: } 5 \text { actors }\end{array}$ & $\begin{array}{l}\text { Private sector: } 5 \text { actors } \\
\text { Agencies: } 9 \text { actors } \\
\text { Civil soc/env: } 1 \text { actor }\end{array}$ \\
\hline Cluster $2(n=3)$ & EG-Agarn, Gew Gampel, Pronat & Local: 3 actors & $\begin{array}{l}\text { Private sector: } 2 \text { actor } \\
\text { Agencies: } 1 \text { actor }\end{array}$ \\
\hline $\begin{array}{l}\text { Cluster } 3(n=2) \\
\text { LR BLV }\end{array}$ & Pro Natura, WWF & Local: 2 actors & Civil soc/env: 2 actor \\
\hline Cluster $1(n=2)$ & LON, VIS TOUR & Local: 2 actors & Private sector: 2 actors \\
\hline Cluster $2(n=10)$ & $\begin{array}{l}\text { EG-VIS, BG-BGL, BG-VIS, LEK BS, VS-DLW, VS-WL, VS- } \\
\text { US, VS-DLR, EMAC, BCI }\end{array}$ & $\begin{array}{l}\text { Local: } 3 \text { actors } \\
\text { Regional: } 7 \text { actors }\end{array}$ & $\begin{array}{l}\text { Agencies: } 7 \text { actor } \\
\text { Civil soc/env: } 3 \text { actor }\end{array}$ \\
\hline \multicolumn{4}{|l|}{ PJV } \\
\hline Cluster $1(n=15)$ & $\begin{array}{l}\text { DL dév dur, Inspecteur, Tour pedeste, DL env, Gestmontagne, } \\
\text { Marchairux, Saveurs, EG Lausanne, EG Nyon, PJV, DL agr, } \\
\text { Tour, Ofagr, ADAEV, Plance d'arme }\end{array}$ & $\begin{array}{l}\text { Local: } 4 \text { actors } \\
\text { Regional: } 9 \text { actors } \\
\text { National: } 2 \text { actors }\end{array}$ & $\begin{array}{l}\text { Private sector: } 5 \text { actors } \\
\text { Agencies: } 6 \text { actor } \\
\text { Civil soc/env: } 4 \text { actor }\end{array}$ \\
\hline Cluster $2(n=3)$ & EPFL, DL devterr, Seco & $\begin{array}{l}\text { Regional: } 1 \text { actors } \\
\text { National: } 2 \text { actors }\end{array}$ & $\begin{array}{l}\text { Private sector: } 1 \text { actor } \\
\text { Agencies: } 2 \text { actors }\end{array}$ \\
\hline
\end{tabular}

The RDC includes 20 actors from all the local and regional levels and from all three sectors; it is split into three sustainability clusters (Table 2). Again, there is one majority cluster including 15 actors. Interestingly, the two minority clusters exclusively consist of local representatives: The first is more driven by economic interests, including one municipality and two private stakeholders, while the second minority cluster consists of two green NGOs. Some local actors thus seem to have more extreme sustainability priorities than the majority of the project participants: some focusing more on economic interests, others more on ecological interests.

The LR BLV is a smaller project only including 12 actors from cantonal and regional level (Table 2). Here, we have one majority cluster, which is opposed to a minority cluster represented by two local private sector representatives.

The PJV is our fourth case not belonging to the Upper Rhone region (Table 2). It is the only project that also includes national actors. Similar to the three other cases, here we also identify a majority and a minority cluster. However, in variance from the other cases, this time it seems that it is mainly national representatives (one research institute; one public agency; and a cantonal agency) who display different sustainability priorities and build a separate group of actors.

To identify potential conflict lines among the actors' groups just identified, we triangulate the cluster results with data we gathered about each organization's concrete interests defended in the respective project (see Appendix 3, ESM).

In the PM Visp case, all actors seem to agree that the project promoted the local economy (mean of 2, Appendix 3 in ESM). Almost all actors disagreed that the PM Visp led to extensive losses of agricultural land; rather considering that it protected infrastructure than humans from natural hazards; and nature conservation is neglected. The only statement slightly dividing the survey participants was the question of whether the project met its goal of human protection from natural hazards (Appendix 1). The majority cluster was much more convinced about this main project goal (mean of 1.21, Appendix 3) and the related outcome than the minority cluster (mean of 1.67, Appendix 3). However, no real conflict line among the clusters could be identified based on the content analysis related to project aims and actors' interests. 
In the RDC case, actors seem to largely agree on the fact that the project does not meet its main goal, e.g., sustainable and long-term protection of the region from natural hazards through regional planning measures (Appendix 3). The two minority clusters (means of 1.34 and 1, Appendix 3 ) seem much more critical to the project than the majority cluster (mean of 1.87, Appendix 3) in this regard. The two green NGOs (cluster 3) also agree that nature protection suffered in comparison with the promotion of local economic interests. In general, the three clusters do not drastically disagree on the three project-related issues asked, but a clear disequilibrium between economic and local performance versus ecological interest might be one explanation for the split among actors in this project.

In the BLV project, the minority cluster consisting of two local private representatives evaluates the three issues asked in a very different way to the majority cluster (Appendix 3). The minority cluster strongly agrees that agriculture and local interests largely suffer from the project. One of the three technical measures for climate change adaptation in the region is the widening of the riverbed to increase runoff capacity. Two rural municipalities with long agricultural traditions are affected by this measure, which might explain the conflicts that arise between different actors participating in the project design.

Finally, most actors involved in the PJV project disagree that the integrated management of the park is only about local tourism promotion; that it does not solve the water scarcity problem in the region; and that scenic beauty is not insured (Appendix 3).

Importantly, the two clusters seem to disagree on one major focus point of the PJV project: the protection of wooded pastures (means of 3.2 and 4, respectively, Appendix 3). The protection of this environmental and cultural heritage was the decisive reason for the creation of

Table 3 Densities within and across groups in collaboration networks

\begin{tabular}{llll}
\hline & Cluster 1 & Cluster 2 & Cluster 3 \\
\hline PM Visp & & & \\
Cluster 1 & 0.26 & 0.16 & \\
Cluster 2 & 0.23 & 0.17 & \\
RDC & & & 0.5 \\
Cluster 1 & 0.39 & 0.38 & 0.33 \\
Cluster 2 & 0.21 & 0.00 & 1.00 \\
Cluster 3 & 0.39 & 0.67 & \\
LR BLV & & & \\
Cluster 1 & 0.00 & 0.00 & \\
Cluster 2 & 0.10 & 0.21 & \\
PJV & & & \\
Cluster 1 & 0.23 & 0.16 & \\
Cluster 2 & 0.27 & 0.00 & \\
\hline
\end{tabular}

the park. The minority cluster and therefore mainly the national actors integrated in the project seem to agree that this project goal was met. From expert interviews conducted in the region, we know that local and cantonal actors mainly seem to feel that national actors do not care a great deal about the conservation of wooded pastures. This could also be one reason why more national, rather than local and cantonal, actors decisively agreed that the project met this goal.

In a final step, we investigate relational patterns in the collaboration network. More concretely, here we are interested in the collaboration within and across the clusters identified above. Table 3 below displays within (the diagonals)- and across-cluster densities.

In the PM Visp project, the highest amount of collaboration $(0.26)$ occurs within cluster 1 . However, cluster 1 also engages in collaboration relations with cluster $2(0.16$ and 0.23 , respectively; Table 3 ). Interestingly, the lowest density happens within cluster 2: Three actors do not strongly collaborate with each other. Inter-collaboration thus happens in the PM Visp case, and the three actors in cluster 2 seem to be well embedded in the overall network, but connect badly with each other.

Even more accentuated compared with the PM Visp case, clusters 1 and 2 in the RDC have a considerable collaboration, respectively, no collaboration at all within the own cluster, but engage in cross-cluster collaboration (Table 3). One exception is cluster 3: The two green NGOs strongly collaborate with each other, have a high collaboration with members of the other minority cluster 2 , and also collaborate with members from cluster 1 . Besides cluster 3, there is no clear intra-cluster collaboration identifiable in the RDC case: Collaboration happens among all members of the network.

Overall, there is not a great deal of collaboration in the BLV project: Densities are low (Table 3). Cluster 2 displays a higher intra- than inter-cluster collaboration, but cluster 1 seems rather passive and the two private actors do not seem to engage in any relational exchange.

Similar to the PM Visp and RDC, the minority cluster of the PJV does not engage in intra-cluster collaboration (Table 3), but is well connected to cluster 2 (0.156 and 0.27 , respectively). In this case, cross-cluster collaboration is also possible and seems to be important in the design process of this regional park project.

\section{Discussion}

Climate change impacts mainly affect local communities, have short-term effects, and call for long-term solutions, which is why sustainable planning processes are viewed as both important and appropriate: They should guarantee the 
horizontal and vertical collaboration of diverse actor types in multi-level governance settings and follow a long-term perspective. Taking into account actors' sustainability perceptions, project-related interests, and network relations, we investigated how sustainability principles are put into practice by comparing four different case studies in Swiss mountain regions.

Discussing first the cross-sectoral characteristics of sustainability, we observed that all four climate adaptation projects involve actors from different decisional levels and representing various sectors. But when looking what sustainability dimensions (namely the inclusion of ecological, social, and economic concerns) actors involved in local climate change adaptation prioritize, it becomes clear that the perceptions of actors diverge. This is an important finding for two reasons: First, it confirms that even in projects (as in the four cases investigated here) where sustainability is introduced as a guiding principle for policy design by the next higher decisional level, there is no guarantee that actors understand this formal principle in the same way. Disparities from policy design in decision-making toward implementation seem to be the logical consequences (Torenvlied and Thomson 2003). Second, and related to the first point, the perception of actors involved in climate adaptation matters in order to grasp context specificities and localized sustainability understanding (Hartmuth et al. 2008). This point seems particularly true when taking local actors' priorities and interests into account and will be discussed further below.

Through the analysis of the priorities that actors attribute to the three sustainability dimensions (ecological, social, and economic), we could identify a clear split into clusters for all four projects. In all four cases, there seems to be a majority cluster integrating most of the actors and one to two minority clusters. For the three cases in Upper Rhone Valley, the minority clusters predominantly contain local actors: Representatives of local communities thus seem to have rather different sustainability definitions and priorities to the large number of diverse actors integrated in the majority cluster. The climate adaptation literature emphasizes the fact that those local communities that live in a setting where ecosystems provide a large array of goods and services are, however, highly sensitive to both socioeconomic and physical (climate) changes (Beniston 2004). It has already been observed that actors living in close spatial proximity to a natural resource or affected area tend to evaluate economic performance and ecological conditions within a given societal arrangement in a very different way to actors at greater distance (Newig and Fritsch 2009; Koontz 1999), which seems to be confirmed again here.

One possible explanation why actors attribute different priorities to the sustainability dimensions are case-related factors and the different interests they have within the respective project. If very different interests are at stake, potential conflict lines and divergent sustainability priorities between actors' groups could arise. Typically in cases where huge conflict lines exist, the implementation of cross-sectoral, long-term, and sustainable management processes might be challenged. Such divergent interests could be observed in the cases of RDC and BLV, where the two minority clusters would have liked the project to take up more local or environmental interests, respectively. In PJV, the situation is very different: We remember that it is the only case not located in the Rhone Valley and where national actors also responded the survey. Those national representatives seem to more widely agree that major project goals (wooded pasture conservation) are met than the local actors who are integrated in the majority cluster. Again, one explanation for this rather critical evaluation of policy goals and instruments by local actors might be their strong affectedness. Local communities are most directly concerned by policy fields in general, and climate adaptation in particular: They are directly addressed by policy instruments that they should implement and practices that they should adopt (Khailani and Perera 2013; Knoepfel et al. 2009), which might explain their rather ambiguous evaluation of the projects here.

We cannot conclude that those diverging interests represented within each project are one decisive source that explains the different sustainability definitions across clusters. But, it is nevertheless interesting to see that actors having divergent sustainability priorities also disagree on some major objectives and goals of the projects they are jointly involved in.

Finally, we tested for inter- and intra-cluster collaboration to further assess cross-sectoral coordination, while also assessing trends for long-term actors' coordination in climate adaptation policies. In cases of high intra- and low inter-cluster collaboration, cluster boundaries are, by definition, very strong and it is difficult to implement collaboration across groups and thus the principle of sustainability.

In PM Visp and BLV, we identified clear clusters each having different sustainability priorities, but with very strong collaboration among cluster members. However, collaboration also happens across clusters. More concretely, clusters seem to collaborate within a project even if they disagreed on one or more of the objectives of the project. We can conclude that divergences in the assessment of a project do not prevent actors from further collaboration with disagreeing clusters. Such inter-cluster collaboration is particularly strong in the PJV case, as well as for clusters 1 and 2 in RDC: Collaboration among cluster members is very weak or nearly absent, but actors tend to collaborate with members from opposite clusters. 
Such inter-cluster collaboration among actors having divergent sustainability priorities and defending different interests within the respective project can be evaluated as a promising precondition for multi-level coordination: actors who interact have the potential to exchange opinions, to engage in mutual learning processes, and to build trust (Newman and Dale 2007; Coleman 1990). Ultimately, this could lead to fostering the second sustainability characteristic, namely long-term planning and an inter-generational perspective. Fostered social relations are said to be mobilized to facilitate collective action (Adler and Kwon 2002) and adaptive capacity (Pelling and High 2005; Ostrom 1990). But, the positive effect of network structures on adaptive capacity can be challenged when actors tend to predominantly collaborate with their peers, and not with others defending different interests or stakes. Such a situation can be observed in the case of cluster 3 in the RDC project: The two green NGOs collaborate intensely, but are not well involved in the collaboration patterns of the whole network. Besides having different sustainability priorities to the other actors and criticizing the RDC for not taking ecological concerns enough into consideration, they are also fairly isolated in the collaboration network. This situation is thus contrary to the cross-sectoral and multi-level definition of sustainable climate adaptation. Concluding about intra- and inter-cluster collaboration, this research has shown that interaction still mainly exists among actors who share same priorities and defend similar interests. But, cross-cluster collaboration and inter-group collaboration are possible: In the cases of PJV and RDC, where sustainability principles were not strongly linked to financial incentives and were introduced by the regional rather than the national authorities, cross-cluster collaboration was sometimes even stronger than intra-group collaboration.

\section{Conclusion}

The aim of this paper was to investigate the implementation of the sustainability in the Upper Rhone Valley through the cross-sectoral and multi-level collaboration of actors in climate adaptation policies. Those collaboration patterns were investigated through actors' sustainability perceptions and network relations applying cluster and social network analysis.

One major conclusion of this research is that collaboration can happen among actors sharing very different views on the macro (related to sustainability)- and the micro-level (related to the project they are involved in). Whether cross-group interaction can last over time and lead to enhanced adaptive capacity toward climate change impacts has still to be demonstrated. To investigate the long-term characteristics of sustainable management, further long-term research designs and longitudinal data gathering would be necessary in the future.

\section{References}

Adger WN (2003) Social capital, collective action, and adaptation to climate change. Econ Geogr 79(4):387-404

Adler PS, Kwon SW (2002) Social capital: prospects for a new concept. Acad Manag Rev 27(1):17-40

Beniston M (2004) Climatic change and its impacts - an overview focusing on Switzerland. Kluwer Academic Publisher, Dordecht/ Boston/London

Bolleyer N, Börzel T (2010) Non-hierarchical policy coordination in multilevel systems. Eur Polit Sci Rev 2(2):157-185

Coleman JS (1990) Foundation of social theory. Harvard University Press, Cambridge

Crona BI, Bodin Ö (2006) What you know is who you know? Patterns of communication as prerequisites for co-management. Ecol Soc 11(2):7. http://www.ecologyandsociety.org/vol11/iss2/art7/. Accessed 6 May 2013

Davies AR (2005) Local action for climate change: transnational networks and the Irish experience. Local Environ 10(1):21-40

Eakin H, Lemos MC (2010) Institutions and change: the challenge of building adaptive capacity in Latin America. Glob Environ Chang 20:1-3

FOEN (2009) Pärke von nationaler Bedeutung: Produktelabel. Richtlinie zur Verleihung und Verwendung des Produktelabels. Federal Office for the Environment, Bern, $\mathrm{CH}$

Gavazov KS, Peringer A, Buttler A, Gillet F, Spiegelberger T (2013) Dynamics of forage production in pasture-woodlands of the Swiss Jura Mountains under projected climate change scenarios. Ecol Soc 18:38

Gehrlein U (2004) Nachhaltigkeitsindikatoren zur Steuerung kommunaler Entwicklung. VS Verlag für Sozialwissenschaften, Wiesbaden

Hamdouch A, Zuindeau B (2010) Sustainable development, 20 years on: methodological innovations, practices and open issues. J Environ Plan Manag 53:427-438

Hanneman RA, Riddle M (2005) Introduction to social network methods. University of California, Riverside, Riverside

Hartmuth G, Huber K, Rink D (2008) Operationalization and contextualization of sustainability at the local level. Sustain Dev 16:261-270

Ingold K, Balsiger J, Hirschi C (2010) Climate change in mountain regions: how local communities adapt to extreme events. Local Environ 15(7):651-661

IPCC (2001) IPCC third assessment report-Climate change 2001: Working Group II: impacts, adaptation and vulnerability. Cambridge University Press, Cambridge, UK. http://www. grida.no/publications/other/ipcc_tar/. Accessed 22 Apr 2013

IPCC (2007) Summary for policymakers, contribution of Working Group I. Cambridge University Press, Cambridge/New York. http://www.ipcc.ch. Accessed 22 Apr 2013

Jänicke M, Jörgens H (2006) New approaches to environmental governance. In: Jänicke $\mathrm{M}$, Jacob $\mathrm{K}$ (eds) Environmental governance in global perspective. New approaches to ecological modernisation. Freie Universität Berlin, Department of Political and Social Sciences, Berlin, pp 167-209

Kenis P, Schneider V (1991) Policy networks and policy analysis: scrutinizing a new analytical toolbox. In: Marin B, Mayntz R (eds) Policy networks: empirical evidence and theoretical considerations. Westview Press, Boulder, pp 25-59 
Khailani D, Perera R (2013) Mainstreaming disaster resilience attributes in local development plans for the adaptation to climate change induced flooding: a study based on the local plan of Shah Alam City, Malaysia. Land Use Policy 30(1):615-627

Knoepfel P, Nahrath S, Savary J, Varone F (2009) Analyse des politiques publiques de l'environnement. Editions Rüegger, Zürich/Chur

Knoke D, Pappi FU, Broadbent J, Tsujinaka Y (1996) Comparing policy networks: labour politics in the US, Germany and Japan. Cambridge University Press, Cambridge

Koontz T (1999) Citizen participation: conflicting interests in state and national agency policy making. Soc Sci J 36(3):441-458

Laumann EO, Knoke D (1987) The organizational state: social choice in national policy domains. University of Wisconsin Press, Madison

Layard A (2001) Introduction: sustainable development-principles and practice. In: Layard A, Davoudi S, Batty S (eds) Planning for a sustainable future. Spon Press, London, pp 1-5

Lubell M, Fulton A (2007) Local policy networks and agricultural watershed management. J Publ Adm Res Theor 18(4):673-696

Newig J, Fritsch O (2009) Environmental governance: participatory, multi-level-and effective? Env Pol Gov 19:197-214

Newman L, Dale A (2007) Homophily and agency: creating effective sustainable development networks. Environ Dev Sustain 9(1):79-90

Nohrstedt D, Ingold K (2011) Venue access and policy conflict: belief system alignment in Swiss and Swedish energy policy subsystems. In: Presented at the Midwest Political Science Association Conference, section 50: public policy, March 30-April 3 2011, Chicago, USA

Ostrom E (1990) Governing the commons. The evolution of institutions for collective action. Cambridge University Press, Cambridge

Parris TM, Kates RW (2003) Characterizing and measuring sustainable development. Annu Rev Environ Resour 28:559-586
Pelling M, High C (2005) Understanding adaptation: what can social capital offer assessments of adaptive capacity? Glob Environ Chang 15(4):308-319

Pelling M, High C, Dearing J, Smith D (2008) Shadow spaces for social learning: a relational understanding of adaptive capacity to climate change within organisations. Environ Plan A 40(4):867-884

Prell C, Hubacek K, Reed M (2009) Stakeholder analysis and social network analysis in natural resource management. Soc Nat Resour 22(6):501-518

Scott J (2000) Social network analysis. Sage, London

Smit B, Pilifosova O (2001) Adaptation to climate change in the context of sustainable development and equity. In: McCarthy JJ, Canziani OF, Leary NA, Dokken DJ, White KS (eds) Climate change 2001: impacts, adaptation, and vulnerability, contribution of Working Group II to the third assessment report of the Intergovernmental Panel on Climate Change. Cambridge University Press, Cambridge, pp 877-912

Smit B, Wandel J (2006) Adaptation, adaptive capacity and vulnerability. Glob Environ Chang 16:282-292

Torenvlied R, Thomson R (2003) Is implementation distinct from political bargaining? Ration Soc 15:64-84

Wall E, Marzall K (2006) Adaptive capacity for climate change in Canadian rural communities. Local Environ 11(4):373-397

Wasserman S, Faust K (1994) Social network analysis: methods and applications. Cambridge University Press, Cambridge

Weible CM, Sabatier PA (2005) Comparing policy networks: marine protected areas in California. Policy Stud J 33(2):181-202

Wenger E (2000) Communities of practice and social learning systems. Organization 7(2):225-246

Wilson E (2006) Adapting to climate change at the local level: the spatial planning response. Local Environ 11(6):609-625 